\title{
Análise das propriedades mecânicas dos fêmures de coelhos submetidos a dietas com diferentes concentrações de flúor
}

\section{Mechanical analysis in femurs of rabbits submitted to diets with different fluoride concentrations}

\author{
Luiz Carlos de Paula Mello, ${ }^{\star}$ José Baptista Volpon,"* Antônio Carlos Shimano, ${ }^{\star \star \star ~ R o n a l d o ~ D e s s i m o n i ~ C a r r e g a l ~ * * \star * ~}$
}

\begin{abstract}
Resumo
Neste estudo objetivamos avaliar a influência do flúor proveniente do fosfato natural de rocha nas propriedades mecânicas dos fêmures de coelhos submetidos a dietas contendo diferentes concentrações de flúor, mediante ensaios mecânicos de flexão em três pontos. Para tanto foram utilizados os fêmures de 40 coelhos machos, albinos, da raça Nova Zelândia. Durante 40 dias, os animais, divididos em cinco grupos, receberam dietas contendo diferentes concentrações de flúor. $O$ ensaio de flexão foi realizado em 77 fêmures para obtenção das seguintes propriedades mecânicas: limite máximo, limite proporcional, rigidez e resiliência. As propriedades mecânicas da deformação proporcional e resiliência apresentaram diferença estatisticamente significante entre os grupos com menor concentração de flúor quando comparados com o grupo 5 . Houve redução nos valores para rigidez, carga máxima, mas sem diferença estatisticamente significante, para os grupos com maior concentração de flúor quando comparados com o grupo testemunha, concluindo-se que houve influência do flúor proveniente do fosfato natural de rocha em algumas propriedades mecânicas.
\end{abstract}

Palavras-chave: propriedades mecânicas; osso; flúor; coelho.

\begin{abstract}
High levels of fluoride ingestion may interfere with bone mineralization and, therefore, cause modification in the bone mechanical properties. In this investigation we studied the relationship between some mechanical properties of the rabbit femur and different concentrations of fluoride in the diets. It was performed the three bending test in forty femurs obtained from New Zealand white rabbits that had been fed with diet with different fluoride concentration during 40 days since they were one month old. The animals were divided into 5 different groups according to the fluoride concentration in diets. The resilience and proportional deformation were higher for the group with the highest fluoride ingestion and there was no difference among the other groups. Rigidity, ultimate load and tension were lower as fluoride concentration increased but with no statistical difference. It was concluded that more investigation is necessary to establish the relationship of the mechanical properties with fluoride intake.
\end{abstract}

Keywords: mechanical properties; bone; fluoride; rabbit

\section{Introdução}

$O$ uso de fosfato natural de rocha como fonte de Ca e $P$ nas dietas para animais domésticos objetiva reduzir a quantidade de produtos importados como o fosfato bicálcico, diminuindo o custo de produção das rações.

Contudo, o seu uso pode ser prejudicial às características ósseas, devido à ausência de padronização dos conteúdos de fósforo, de cálcio e de flúor (Junqueira, 1991; Guinotte et al., 1991).

Segundo Gomes et al. (1989), a avaliação da toxidez do flúor nos ossos torna-se necessária para avaliar o prejuízo provo- cado nos animais adultos e em crescimento. Nos animais em crescimento, o flúor interfere na mineralização óssea por formar complexo com o cálcio e fósforo, que os tornam indisponiveis para absorção e utilização no metabolismo orgânico.

Kleerekoper (1996) relatou os efeitos profundos de fluoretos no esqueleto, podendo ser benéficos, no caso de serem estabelecidas dosagens limitadas ou prejudiciais, quando ingeridos em grandes concentrações. Este autor concluiu que são necessários mais estudos clínicos e investigações sobre o metabolismo destes minerais.

Apesar das diferenças entre os materiais biológicos e os materiais usados na engenharia, os equipamentos moder-

\footnotetext{
* Zootecnista - Mestre em bioengenharia (Faculdade de Medicina de Ribeirão Preto (FMRP-USP) - Bolsista FAPESP.

** Professor Associado do Depto. de Cirurgia, Ortopedia e Traumatologia (Laboratório de Bioengenharia - FMRP-USP).

*** Doutor em Engenharia Mecânica (Laboratório de Bioengenharia - FMRP-USP).

**** Professor Doutor do Departamento de Nutrição Animal - (UNESP - Jaboticabal).
} 
nos utilizados nestas áreas sugerem temas de estudo na interface. Algumas técnicas de análise estática e dinâmica utilizadas em engenharia podem ser adaptadas aos estudos de ossos, assim como alguns equipamentos das áreas médicas produzem resultados que podem ser manipulados para obtenção de propriedades de materiais.Os ensaios mecânicos de materiais têm como objetivo determinar o maior número de características, que podem ser classificados em: ensaios destrutivos e não-destrutivos. Os ensaios destrutivos são caracterizados pela destruição dos corpos de prova ou modelos após os ensaios realizados e os não-destrutivos são aqueles em que não há destruição, podendo até ser executado em peça já acabada. Os ensaios destrutivos são os ensaios mecânicos em geral (tração, compressão, flexão, torção e cisalhamento), e os ensaios não-destrutivos são, por exemplo: raios $x$, ultra-som e ressonância magnética (Fraccaroli, 1981).

Dentre os autores que realizaram estudos experimentais avaliando a influência dos níveis de flúor nas propriedades mecânicas destacam-se Burnell et al. (1986) que verificaram que niveis acima de sete partes por milhão (ppm) de flúor nas dietas para suínos afetaram a integridade do osso e diminuíram significativamente a tensão de ruptura e o módulo de elasticidade.

Furlan et al. (1994), utilizando fosfatos naturais de rocha como fonte de flúor na alimentação de coelhos, determinaram a resistência óssea por meio do ensaio de compressão simples. Os resultados mostraram que a média da resistência à compressão foi menor nos fêmures dos animais tratados com fosfato natural de rocha, quando comparados com os fêmures dos animais tratados com fosfato bicálcico, isento de flúor.

Chan et al. (1973), trabalhando com ossos de aves, verificaram que 0 alto teor de flúor na dieta influenciou a mineralização do osso, promovendo maior retenção de cálcio, porém reduzindo a resistência à torção óssea em $30 \%$.

Walsh e Guzelsu, em 1994, realizaram ensaios mecânicos de compressão em osso cortical de suínos para avaliar a interação de fluoretos com a mineralização óssea e as propriedades mecânicas, verificando alterações significativas nos limites de proporcionalidade e máximos e, também, na rigidez.

Este experimento objetivou estudar e avaliar as propriedades mecânicas de fêmures de coelhos submetidos a dietas com diferentes concentrações de flúor, com ensaio mecânico de flexão em três pontos.

\section{Material e método}

\section{Animal utilizado}

Para os ensaios mecânicos, foram utilizados 40 coelhos albinos, da raça Nova Zelândia, machos, recém-desmamados com 30 dias de idade. Foram alojados dois animais por gaiola, cada par de animais teve sua ração separada em recipientes próprios, para melhor controle da ração ingerida por gaiola. Aos 70 dias de idade, os animais foram pesados e sacrificados com golpe na nuca.

\section{Rações}

De acordo com o NAS (National Academy of Sciences) de 1980, níveis acima de 40 ppm de flúor dietético fornecidos ao coelho tornam-se prejudiciais ao seu organismo. Baseados nestas informações, foram formuladas rações para conterem concentrações diferentes de flúor. Os animais destinados ao ensaio mecânico foram divididos em cinco grupos (oito animais), de acordo com a concentração do flúor na ração.

Grupo 1 = Ração testemunha contendo traços de flúor

Grupo 2 = Ração contendo 25 ppm de flúor

Grupo 3 = Ração contendo 35 ppm de flúor

Grupo 4 = Ração contendo 45 ppm de flúor

Grupo 5 = Ração contendo 55 ppm de flúor

\section{Coleta dos ossos}

De cada animal foram retirados os fêmures que foram dissecados, identificados, envolvidos por gazes embebidas em solução fisiológica e congelados em freezer à temperatura de $-20^{\circ} \mathrm{C}$, até o momento do ensaio.

\section{Máquina universal de ensaios}

A máquina universal de ensaios, pode ser utilizada para realizar qualquer tipo de ensaio mecânico estático que se desejar, desde que se utilize o acessório adequado, principalmente quando necessitar combinações de diferentes tipos de esforços como, por exemplo, esforços de flexão e compressão.

Os parâmetros importantes que devem ser levados em consideração são: velocidade de aplicação de carga, pré-carga e tempo de acomodação. A velocidade de aplicação de carga depende do tipo de material a ser ensaiado, velocidade maior para materiais mais elásticos, como músculos e ligamentos, e velocidade menor para materiais mais rígidos, como os ossos. A importância da pré-carga e do tempo de acomodação é para eliminar as possiveis folgas existentes nas garras (acessórios) da máquina e para que haja uma padronização dos ensaios a serem realizados.

\section{Ensaio mecânico}

Os ossos foram retirados do freezer 24 horas antes do ensaio.

Os ensaios mecânicos de flexão em três pontos foram realizados em 77 fêmures dos coelhos, no Laboratório de Bioengenharia (FMRP-USP), em máquina universal de ensaio. Nos ensaios de flexão em três pontos os fêmures foram apoiados sobre dois suportes distanciados de $55 \mathrm{~mm}$. Foi utilizada uma célula de carga KRATOS $₫$ modelo KM, com capacidade de até $200 \mathrm{kgf}$, ligada a uma ponte de extensometria SODMEX®, modelo CAE 201. As deflexões foram registradas por um relógio comparador Mitutoyo $\circledast$ com precisão de centésimos de milimetros (Figura 1).

Foi utilizada pré-carga de $0,5 \mathrm{~kg}$ f para acomodação do sistema: máquina, acessórios e osso, com um tempo de acomodação de 1 minuto. A velocidade de aplicação da carga utilizada foi de $0,50 \mathrm{~mm} / \mathrm{min}$. 


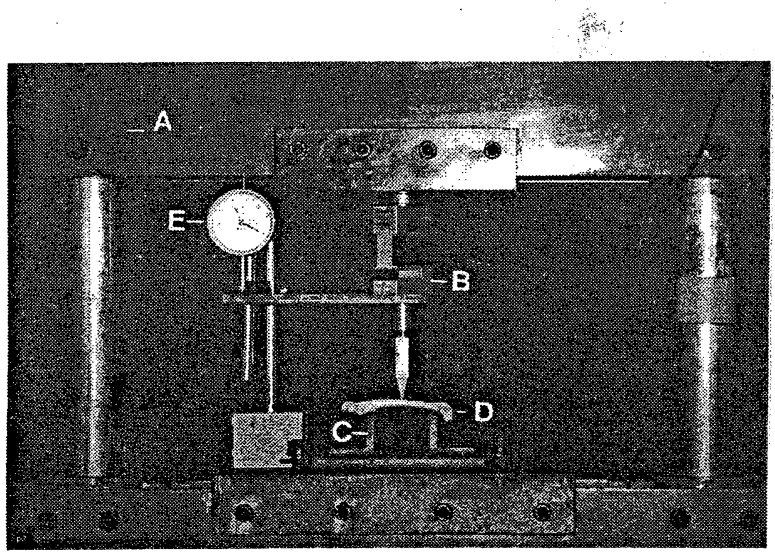

Figura 1: Montagem para a realização do ensaio de flexão em três pontos. Conjunto na máquina universal de ensaios (A): Célula de carga (B), suportes (C), osso (D) e relógio comparador (E).

Com base nos valores obtidos, foram confeccionados os gráficos carga $x$ deflexão (Figura 2) para cada osso ensaiado, e a partir das curvas, foram calculadas as seguintes propriedades mecânicas: limites de proporcionalidade (LP), limites máximos $(L M)$, rigidez $(R)$ e resiliência $(E)$.

LP - identificado como sendo o último ponto onde se encontra o segmento reto da curva carga $x$ deflexão.

LM - são os maiores valores da carga e deflexão observados em cada ensaio (ponto máximo)

R - é obtida na fase elástica do material, determinada pela inclinação da curva carga $x$ deflexão,

E - energia absorvida na fase elástica, obtida através do cálculo da área formada pela região elástica

\section{Análise estatística}

Foi utilizado o teste de Tukey com procedimento GLM (General Linear Model) do software SAS (Statistical Analysis System, 1990) para verificar se houve diferença significativa entre os tratamentos. O nivel de significância foi estabelecido em $5 \%$.

\section{Resultados e discussão}

A Tabela 1 apresenta as médias e o desvio-padrão das propriedades mecânicas obtidas nos ensaios de flexão.

Tabela 1: Valores médios das propriedades mecânicas obtidas nos ensaios de flexão em três pontos dos ossos para os diferentes grupos

\begin{tabular}{lccccc}
\hline $\begin{array}{l}\text { Propriedades } \\
\text { Mecânicas }\end{array}$ & 1 & 2 & 3 & 4 & 5 \\
\hline$C_{\text {máx }}(\mathrm{N})$ & $250,14 \pm 42,18$ & $256,42 \pm 17,98$ & $239,45 \pm 44,61$ & $230,33 \pm 51,06$ & $246,03 \pm 27,35$ \\
$D_{\text {maxx }}\left(\times 10^{-3} \mathrm{~m}\right)$ & $1,30 \pm 0,16$ & $1,33 \pm 0,14$ & $1,22 \pm 0,14$ & $1,49 \pm 0,28$ & $1,37 \pm 0,16$ \\
$\mathrm{C}_{\text {prop }}(\mathrm{N})$ & $176,83 \pm 25,23$ & $188,07 \pm 21,94$ & $171,92 \pm 35,94$ & $163,82 \pm 50,43$ & $198,85 \pm 35,21$ \\
pprop $\left.^{*} \times 10^{-3} \mathrm{~m}\right)$ & $0,64 \pm 0,07^{\mathrm{a}}$ & $0,64 \pm 0,04$ & $0,63 \pm 0,08^{\mathrm{a}}$ & $0,64 \pm 0,11$ & $0,75 \pm 0,14^{\mathrm{b}}$ \\
$\mathrm{R}_{\left(\times 10^{3} \mathrm{~N} / \mathrm{m}\right)}$ & $275,51 \pm 48,87$ & $290,33 \pm 27,23$ & $269,75 \pm 38,76$ & $244,61 \pm 72,76$ & $268,06 \pm 58,79$ \\
$\mathrm{E}\left(\times 10^{-3} \mathrm{~J}\right)$ & $56,12 \pm 9,62^{\mathrm{a}}$ & $59,98 \pm 9,71$ & $54,13 \pm 16,74^{\mathrm{a}}$ & $53,56 \pm 19,59^{\mathrm{a}}$ & $78,16 \pm 16,24^{\prime}$ \\
\hline
\end{tabular}

* Média numa mesma linha seguida de letras diferentes, indica diferença significativa $(p<0,05)$ entre os tratamentos, pelo teste de Tukey.

Cmáx (N) - carga máxima; Dmáx $\left(\times 10^{-3} \mathrm{~m}\right)$ - deformação máxima; Cprop $(\mathrm{N})$ - carga proporcional Dprop $\left(\times 10^{-3} \mathrm{~m}\right)$ - deformação proporcional; $R\left(\times 10^{3} \mathrm{~N} / \mathrm{m}\right)$ - rigidez; $E\left(\times 10^{-3} \mathrm{~J}\right)$ - resiliência.

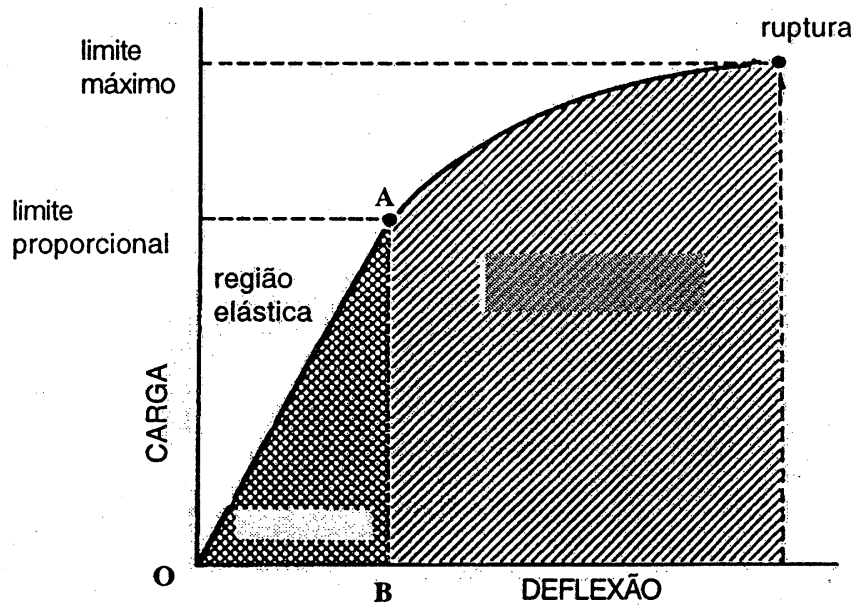

Figura 2: Exemplo de gráfico carga aplicada $x$ deflexão utilizado para determinação das propriedades mecânicas, ilustrando o limite de proporcionalidade (LP), a reta que representa a inclinação da curva (q) e o triângulo formado pela união dos pontos.

Houve diferença estatisticamente significante entre os grupos 1 e 3 quando comparados com o grupo 5 para a deformação proporcional e houve diferença também para a resiliência entre os grupos 1,3 e 4, quando comparados com o grupo 5 . Houve redução nos valores para rigidez, carga máxima, mas sem diferença estatisticamente significante, para os grupos com maior concentração de flúor.

O acúmulo de flúor no esqueleto é influenciado pela sua forma química fornecida na dieta. Nossos resultados diferem de alguns autores, provavelmente, também, pela forma química do flúor presente na ração fornecida aos grupos de coelhos. Neste trabalho o flúor utilizado foi proveniente do fluoreto de cálcio, encontrado em maior parte nas rochas naturais, sendo menos absorvível (Clay et al., 1985), enquanto que outros autores utilizaram o fluoreto de sódio ( $\mathrm{NaF})$, contendo uma forma de flúor mais solúvel.

Mediante ensaios de compressão realizados com ossos de suínos alimentados com dietas contendo fluoretos, Mosekilde et al. (1987) verificaram diminuição nos valores para rigidez, carga máxima e energia absonvida. No presente trabalho constatamos, também, esta diminuição, embora sem diferença estatisticamente significativa, na rigidez e na carga máxima, e, entre alguns tratamentos, houve diferença significativa para resiliência.

Diante destas considerações e de nossos achados comparados com outros autores, fica evidente a necessidade de mais investigações para determinar como o flúor pode atuar nas propriedades mecânicas, bem como seus mecanismos.

\section{Conclusão}

A ingestão de níveis elevados de flúor proveniente do fosfato natural de rocha influenciou nas propriedades mecânicas da deformação proporcional e resiliência, nas outras, somente houve uma redução nos valores, sem diferença estatisticamente significante. 


\section{Agradecimentos}

À FAPESP (Fundação de Amparo à Pesquisa do Estado de São Paulo) pelo apoio e concessão da bolsa de pesquisa.

\section{Referências bibliográficas}

BURNEL, T.W., PEO, E.R.Jr., LEWIS, A.J., CRENSHAW, J.D. Effect of dietary fluorine on growth, blood and bone characteristics of growing-finishing pigs. J Anim Sc, Champaign, v. 63, n. 6, p. 20532067, 1986.

CHAN, M.M., RUCKER, R.B., ZEMAN, F., RIGGINS, R.S. Effect of fluoride on bone formation strength in japanese quail. J Nutr, v. 103, n. 10, p. 1431-1440, 1973.

CLAY, A.B., SUTTIE, M.S., SUTTIE, J.W. The availability of fluoride from NaF and phosphorus supplements. Vet Hum Toxicol, v. 27, n. 1, p. 3-6, 1985.

FRACCAROLI, J.L. Biomecânica: análise dos movimentos. 2.ed. Rio de Janeiro: Cultura Médica, 1981.

FURLAN, A.C., TAFURI, M.L., ROSTAGNO, H.S., SILVA, M.A., SCAPINELLO, C., DONZELE, J.L. Uso de fosfato natural de rocha na alimentação de coelhos em crescimento. Rev Soc Bras Zootec, v. 23, n. 5, p. 829-839, 1994.

GOMES, P.C., PEREIRA, J.A. Efeitos das fontes, disponibilidade e nível de fósforo na ração de suínos na fase inicial. Rev Soc Bras Zootec v. 18, n. 3, p. 248-259, 1989.
GUINOTTE, F., NYS, Y., MONREDON, F. The effects os particle size and origin of calcium carbonate on performance and ossification characteristics in broiler chicks. Poult Sci, v. 70, n. 9, p. 1908-1920, 1991.

JUNQUEIRA, O. M. Desempenho produtivo de aves alimentadas com fosfatos não convencionais. In: MINI SIMPÓSIO DO COLÉGIOBRASILEIRODENUTRIÇÃO, 6., Campinas, 1991./Resumos/,p.121-136, 1991.

KLEEREKOPER, M. Fluoride and the skeleton. In: BILEZIKIAN, J.P. etal. Principles of bone biology. Califórnia: Academic Press, Cap. 75, p. 1053-1062, 1996.

MOSEKILDE, L., KRAGSTRUP, J., RICHARDS, A. Compressive strength, ash weight, and volume of vertebral trabecular bone in experimental fluorosis in pigs. Calcif Tissue Int, v. 40, n. 6, p. 318-322, 1987.

NATIONAL ACADEMY OF SCIENCES - NAS. Committee on Animal Nutrition. Mineral tolerance of domestic animals. Washington, 1980, 534 p., 1980.

STATISTICAL ANALYSIS SYSTEMS. Statistical analysis systems user's guide. 4. ed. Cary: SAS Institute, v. 2, 1990.

WALSHW.R., GUZELSU, N. Compressive properties of cortical bone: mineral-organic interfacial bonding. Biomaterials, v. 15, n. 2, p. 137-145, 1994. 